\title{
Effect of Temperature and Moisture on the Tensile Properties of a TEPs-Modified Adhesive
}

\begin{abstract}
MARIANA D. BANEA ${ }^{1,3, *}$, LUCAS F.M. DA SILVA2, RICARDO CARBAS ${ }^{2,3}$, SILVIO DE BARROS ${ }^{1}$
${ }^{1}$ CEFET/RJ - Federal Center of Technological Education in Rio de Janeiro, Brazil.

2Departamento de Engenharia Mecanica, Faculdade de Engenharia, Universidade do Porto, Rua Dr. Roberto Frias, 4200-465 Porto, Portugal.

3INEGI, Faculdade de Engenharia, Universidade do Porto, Rua Dr. Roberto Frias, 4200-465 Porto, Portugal.

The main factors that affect the strength of adhesive joints are the exposure to moist environments and high and/or low temperatures. The objective of this paper is to measure the water diffusion in adhesives modified with thermally expandable particles (TEPs) and assess the joint strength of water saturated modified adhesives. Bulk specimens were used to measure the diffusion coefficient of water in a TEPs-modified adhesive. The tensile data as a function of TEPs content, moisture uptake and temperature was measured. It was found that the presence of moisture and the temperature affect the mechanical properties of TEPsmodified adhesive. Further, a scanning electron microscope (SEM) analysis was performed in order to examine the fracture surfaces of the tensile specimens tested as a function of temperature and water uptake. SEM analysis showed that the absorbed moisture and temperature change the fracture mechanisms and the morphology of the specimens.
\end{abstract}

Keywords: Thermally expandable particles (TEPS), structural adhesives, temperature, water uptake, tensile properties

Adhesives have become the method of choice for many structural joining applications. However, one disadvantage of adhesive joints is the permanent nature of the bond. Several possibilities exist to debond adhesive joins in a controlled manner [1-5]. It has been already shown that with the right amount of TEPs, a bond can be dismantled rapidly with local heat [3-5]. However, one of the concerns associated to this technique is the effect of water on the adhesive properties as the particles can create a path for an increase of water diffusion.

Moisture is absorbed by adhesives in two differentways: as free water, which occupies the free spaces of the adhesive and is responsible for plasticization. Water is also absorbed as bound water, which forms single or multiple hydrogen bonds with the adhesive's polymer chain, resulting in swelling of the adhesive, plasticization and consequent decrease of strength and glass transition temperature $(T)$. Usually, if the water uptake is done at low temperatures, as soon as the adhesive is dried, its mechanical properties are usually recovered. It is usually, therefore, a reversible process [6].

High temperatures are also responsible for degrading the adhesive properties $[7,8]$. Studies that present experimental results of adhesive joints with structural adhesives (especially epoxies) as a function of temperature generally show a decrease in strength with increasing and decreasing temperatures [7]. At high temperatures the cause is the lower adhesive strength while at low temperatures the high thermal stresses and the brittleness of the adhesive are the origin of such behaviour. However, little is known in terms of temperature when it comes to TEPs-modified adhesives.

The objective of this paper is to measure the water diffusion in adhesives modified with TEPs and assess the joint strength of water saturated modified adhesives. Bulk specimens were used to measure the diffusion coefficient of water in a TEPs-modified adhesive. The tensile data as a function of TEPs content, moisture uptake and temperature was measured. Further, a scanning electron microscope (SEM) analysis was performed in order to examine the fracture surfaces of the tensile specimens tested as a function of temperature and water uptake.

\section{Experimental part \\ Materials}

A two-component epoxy adhesive Betamate ${ }^{T M} 2098$, supplied by Dow Automotive (Dow Europe $\mathrm{GmbH}$, Horgen, Switzerland) was selected for this study. This adhesive is used in automotive industry being part of a new generation of crash durable adhesives which combine high level of strength and elongation, and was used by the authors in previous studies about debonding of adhesive joints $[3,4]$. Expancel 031 DU 40 particles supplied by Akzo Nobel Expancel Industries (Sundsvall, Sweden) were selected. The diameter of these particles ranges mainly from 10 to $16 \mu \mathrm{m}$.

\section{Specimens manufacture}

The TEPs-modified adhesive was mixed with a Speed Mixer (DAC 150.1 FVZ Speedmixer, Hauschild, Germany) for $60 \mathrm{~s}$ at $2500 \mathrm{rev} / \mathrm{min}$. This allows an efficient and homogeneous dispersion, creating visibly bubble-free mixing. Thin sheets of the adhesive modified with different TEPs concentration by percentage weight $(0,10$ and 20 $w t \%$ TEPs) were produced by curing the adhesive between steel plates of a mould with a silicone rubber frame (the silicone ensures the thickness of the adhesive plate of $2 \mathrm{~mm}$ ), which were pressed ( $2 \mathrm{MPa}$ ) for $24 \mathrm{~h}$ at room temperature (RT) [9]. From these sheets, bulk tensile specimens (fig. la, b) and water absorption specimens (fig. 1c) were machined.

\section{Measurements and characterization}

Before ageing, the specimens were kept in a dry desiccator in order to eliminate any water that they might be absorbed from the environment until the specimen's weight was constant. Next, the initial weight of each specimen was measured using a microbalance (KernToledo, Balingen, Germany) with a 0.001 g resolution scale. Subsequently, the specimens were aged in distilled water 


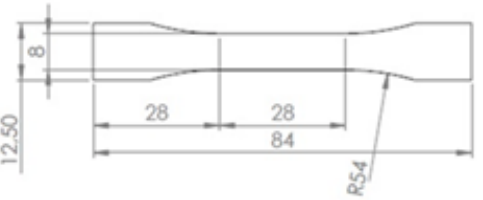

a)

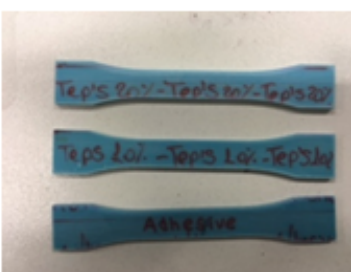

b)

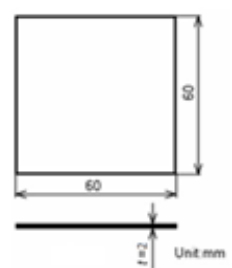

c)

at $32.5^{\circ} \mathrm{C}$. The weight of the specimens was measurec periodically until saturation was achieved. This method is known as the gravimetric method.

The water content was calculated using eq. (1):

$$
M_{t}=\frac{m_{t}-m_{0}}{m_{0}} \times 100 \%
$$

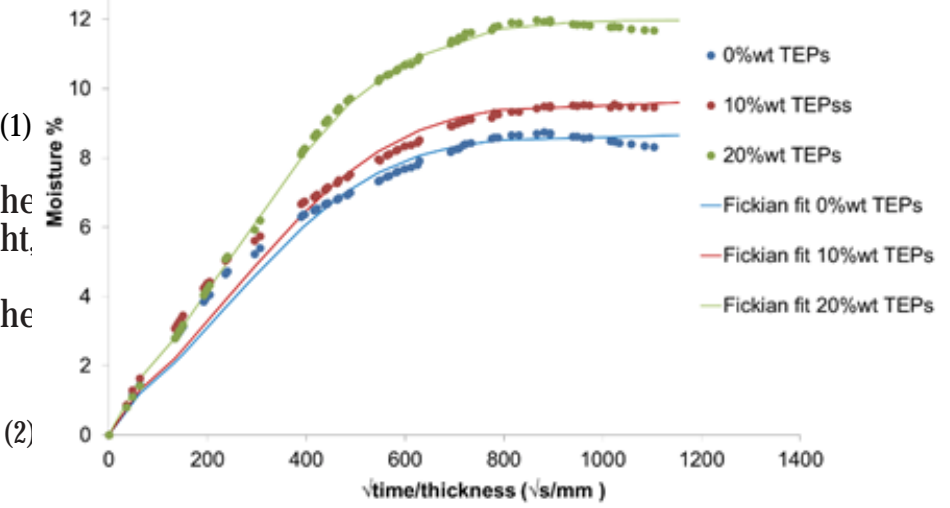

where $D$ is the diffusion rate, $M_{\alpha}$ is the equilibrium water uptake and $h$ is the specimen thickness.

The diffusion rate, $D$ was calculated using eq. (3) when the equilibrium water uptake was obtained:

$$
D=\left(\frac{M_{t}}{M_{\infty}}\right)^{2} \times \frac{\pi}{16} \times \frac{h^{2}}{t}
$$

The bulk dogbone specimens were aged under the same environmental conditions used with the water sorption specimens (i.e. distilled water). The dogbone specimens were tested in tension using a universal testing machine Instron model 3367 (Norwood, Massachusetts, USA), which has a maximum load capacity of $30 \mathrm{kN}$, at room temperature and $80^{\circ} \mathrm{C}$ under a constant crosshead rate of $1 \mathrm{~mm} / \mathrm{min}$. At least five specimens were tested to failure for each case (i.e. TEPs content and condition).

\section{SEM analysis}

A SEM analysis was performed on the fracture surfaces of the dogbone specimens using a high resolution Scanning Electron Microscope with X-Ray Microanalysis: JEOL J SM 6301F/ Oxford INCA Energy 350 (Gatan Alto 2500, Tokyo, Japan) at the CEMUP laboratory (University of Porto, Portugal). Samples were coated with a gold (Au)/ palladium (Pd) thin film (for $120 \mathrm{~s}$ and with a $15 \mathrm{~mA}$ current), by sputtering, using the SPI Module Sputter Coater equipment prior to examination. Secondary electron images were collected at different magnifications ( $x 35, x 200, x 500$, $\mathrm{x} 1000$ ).

\section{Results and discussions}

\section{Water absorption tests}

Figure 2 shows the fractional moisture uptake of the bulk TEPs-modified adhesives versus the square root of time over the thickness, as well as the respective Fickian fit. It can be seen that the water uptake initially increases linearly at the beginning of the exposure and then levels off until equilibrium was attained. It can be noted that the moisture uptake increases as a function of wt\% of TEPs. All the cases (TEPs content) showed a simple Fickian

Fig. 1. Test specimen geometry (dimensions in $\mathrm{mm}$ ): $\mathrm{a}, \mathrm{b}$ ) tensile, c) bulk water absorption

Fig. 2. Water uptake behaviour of the TEPs-modified adhesive.

behaviour. Fickian absorption is the most common type of absorption in adhesives. It happens when diffusion is much slower than relaxation and the water uptake is directly proportional to the square root of exposure time [6].

The absorption behaviour of the adhesive can be quantified by the diffusion coefficient $D$, which is a measure of the ability of the penetrant water molecule, to move among the polymer segments. The water diffusion properties of TEPs-modified adhesives as a function of TEPS content are summarised in table 1.

Effect of temperature and moisture on the mechanical properties of the TEPs-modified adhesive

The effect of moisture on the mechanical behaviour of the TEPs-modified adhesives have been studied by tensile tests of dry and wet (water saturated) specimens, while the effect of temperature was studied by testing the tensile specimens at $80^{\circ} \mathrm{C}$. For each specimen, a tensile stressstrain curve was produced based on load, displacement values and specimen dimensions (fig 3). From the stressstrain curves, the tensile strength and maximum tensile

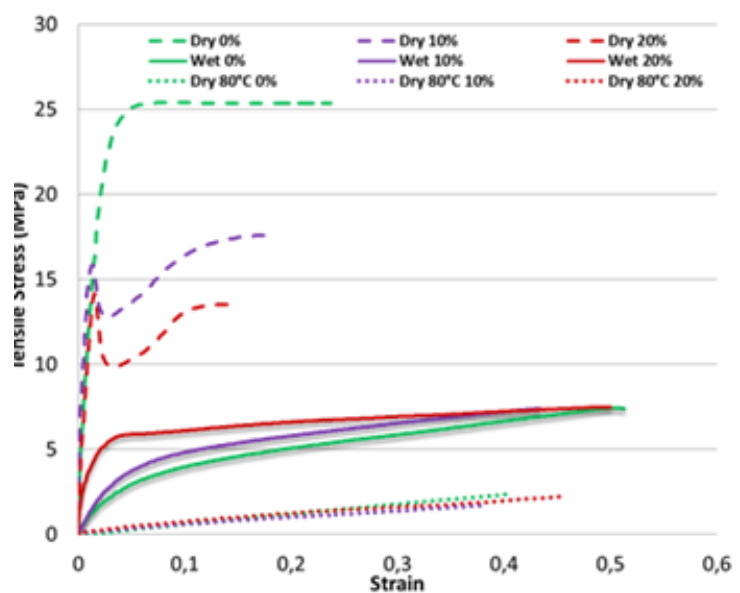

Fig. 3. Representative stress-strain curves of the TEPs-modified adhesive.

Table 1

\begin{tabular}{|c|c|c|c|}
\hline TEPs content & $0 \%$ wt. TEPs & $10 \% w t$. TEPs & $20 \% w t$. TEPs \\
\hline $\mathrm{D}\left[\mathrm{m}^{2} / \mathrm{s}\right]$ & $6.36 \times 10^{-13}$ & $5.83 \times 10^{-13}$ & $5.95 \times 10^{-13}$ \\
\hline $\mathrm{M}_{\infty}[\%]$ & 8.6 & 9.6 & 11.8 \\
\hline
\end{tabular}

WATER DIFFUSION PROPERTIES OF TEPS-MODIFIED ADHESIVES 


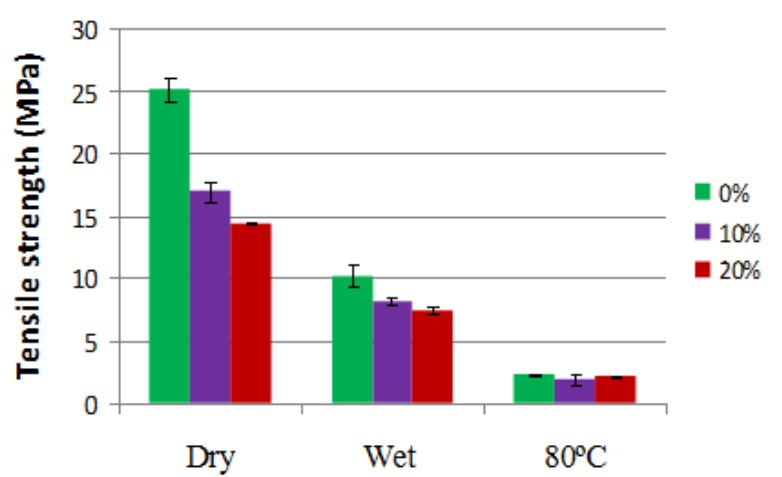

Fig. 4. The tensile strength of the TEPs-modified adhesive.

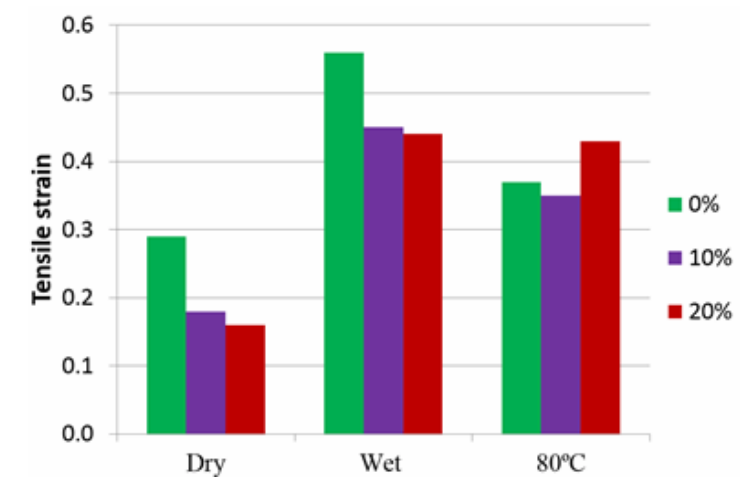

Fig. 5. Tensile strain of the TEPs-modified adhesive strain were calculated and the results can be seen in figure 4 and 5.

As can be seen in figure 4, for dry (unaged) specimens, a significant decrease in adhesive strength with increasing wt $\%$ TEPs content was found (by approximately $32 \%$ for $10 \mathrm{wt} \%$ and approximately $45 \%$ for $20 \mathrm{wt} \%$ ). As the TEPs content increases, the neat adhesive volume decreases, resulting in less strength. The tensile strength of the wet (moisture saturated) group specimens was reduced considerably when compared to dry group specimens. This probably happen because of the plasticization effect of absorbed moisture [10]. It was also shown that the absorbed water can act as a crazing agent continuously decreasing the mechanical strength of epoxies with exposure time in water [11]. At $80^{\circ} \mathrm{C}$, a drastic decrease in adhesive tensile strength was observed. This can be explained by the fact that the test temperature was above the glas transition temperature of the adhesive (i.e. $60^{\circ} \mathrm{C}$ as per supplier). An important aspect that should be noted is that the tensile strength of the samples tested at $80^{\circ} \mathrm{C}$ are only slightly reduced as the TEPs content increase. It can be concluded that the temperature mainly degrade the adhesive matrix and not the particles.

From figure 5 it can be seen that the maximum deformation decreased with increase of TEPs content, by approximately $34 \%$ for 10 wt $\%$, while for 20 wt $\%$ TEPs the adhesive deformation decreased by approximately $45 \%$. The decrease in deformation of TEPs-modified specimens compared with the neat adhesive specimens may be caused by the fact that the high percentages of TEPs with less amount of neat adhesive, makes the adhesive system denser and brittle. The deformation of the wet specimens increased considerably when compared to the dry group specimens (by approximately $93 \%$ for $0 \%$ of TEPs, $150 \%$ for $10 \%$ wt TEPs and $175 \%$ for $20 \%$ wt TEPs, respectively). Moisture increases the flexibility and ductility of the adhesive. For the samples tested at $80^{\circ} \mathrm{C}$, the tensile strain also increased but less compared to wet specimens.

To summarize, large increases in ductility (strain to failure) and reductions in tensile strength were measured for the water saturated samples and $80^{\circ} \mathrm{C}$.

\section{SEM analysis}

In order to investigate the effect of temperature and moisture on the fracture mechanisms and TEPs morphology, a SEM analysis of the fractured surfaces was performed. A considerable amount of information has been reported by the authors, in past studies, on the appearance of fracture surfaces and particles morphology of unmodified and modified TEPs-adhesives $[12,13]$. It was shown that TEPs-modified adhesive samples had a uniform dispersion of particles within the samples no matter of TEPs content and adhesive $[12,13]$. The SEM micrographs of the fracture surface of the dry, wet and $80{ }^{\circ} \mathrm{C}$ specimens as a function of TEPs content are shown in figures 6-8.

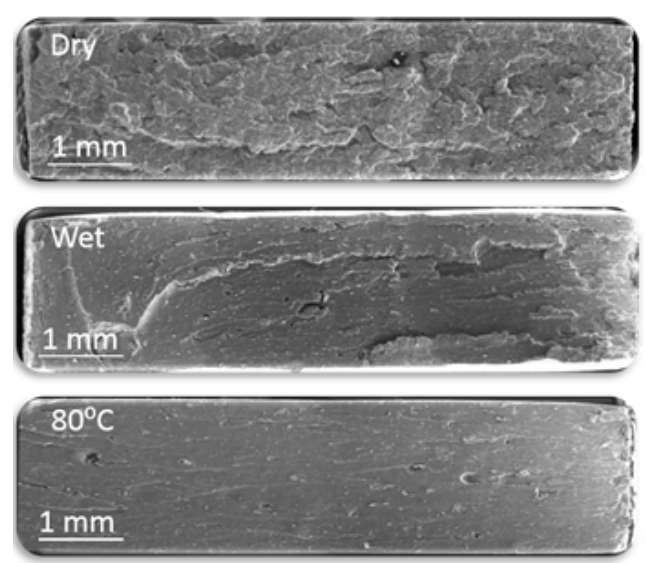

Fig. 6. SEM micrographs of the fracture surface of the dry, wet and $80^{\circ} \mathrm{C}$ specimens for unmodified adhesive.
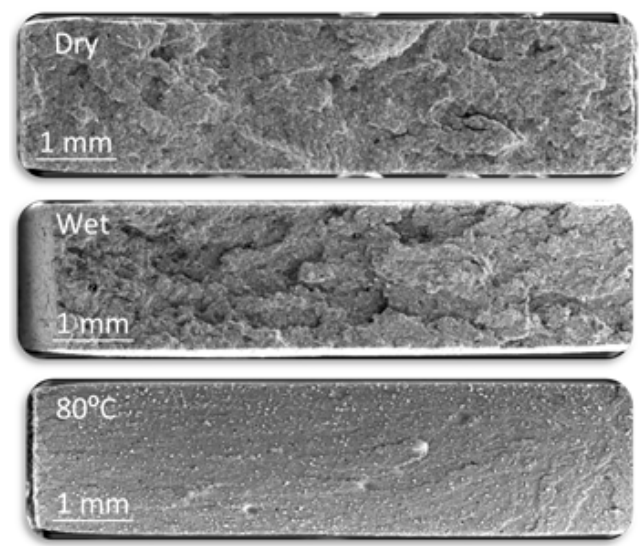

Fig. 7. SEM micrographs of the fracture surface of the dry, wet and $80^{\circ} \mathrm{C}$ specimens for $10 \%$ TEPs-modified adhesive samples
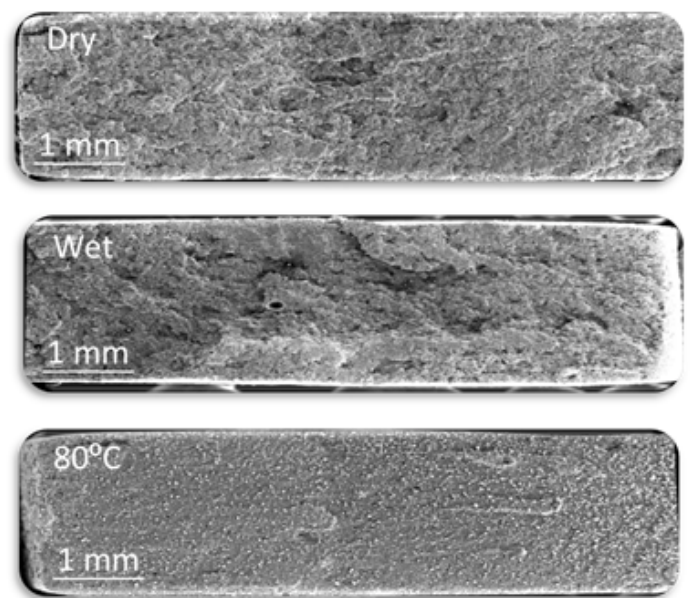

Fig. 8. SEM micrographs of the fracture surface of the dry, wet and $80^{\circ} \mathrm{C}$ specimens for $20 \%$ TEPs-modified adhesive samples. 
It can be seen that the absorbed moisture had deleterious effects on the physical properties of the adhesive and changed the fracture mechanisms. The rougher cleavage pattern for unmodified dry specimens loses it roughness when saturated in water (wet), with no yielding of the adhesive (fig. 6). The change caused by the temperature on the fracture of unmodified adhesive samples can also be clearly observed. This analysis sustain the experimental results where a drastic decrease in tensile strength was found for wet and $80^{\circ} \mathrm{C}$ samples when compared to dry condition. Similar, for TEPs-modified adhesives (figs. 7 and 8 ) the differences in fracture surfaces between the dry, wet and $80^{\circ} \mathrm{C}$, can be clearly observed. It should be noted that apparently the particles were not affected by the moisture uptake. It can be concluded that the tensile properties degradation of the TEPs- modified specimens is mainly due to the degradation of the adhesive matrix.

\section{Conclusions}

In this paper, the effect of temperature and moisture uptake on the behaviour of a structural adhesive modified with TEPs was investigated. The following conclusions can be drawn:

-The water uptake percentage increases with the TEPs content. Absorption obeyed the Fickian diffusion model for all cases studied (TEPs content).

-Due to the effect of ageing, the tensile strength of the studied TEPs-modified adhesive have been reduced. On the other hand, the strain to failure increased, indicating that moisture increases the flexibility and ductility of the adhesive.

-The particles were not affected by the moisture uptake. Thus, the tensile properties reduction of the TEPs- modified specimens is mainly due to the degradation of the adhesive matrix.
-Temperature affects the mechanical properties of the TEPs-modified adhesives. The tensile strength drastically decrease, while the ductility increased.

-SEM analysis showed that temperature and the absorbed moisture change the fracture mechanisms and the morphology of the unmodified and TEPs-modified adhesive.

\section{References}

1. BANEA M.D., da SILVA L.F.M., CAMPILHO R.D.S.G., Annals of Dunarea de Jos University of Galati, Fascicle XII, Welding Equipment and Technology, 24, 2013, p. 11;

2. BANEA M.D., da SILVA L.F.M., CAMPILHO R.D.S.G., SATO C., J. Adhes., 90, 2014, p. 16;

3. BANEA M.D., da SILVA L.F.M., CARBAS R.J .C, Int. J. Adhes. Adhes., 59, 2015, p. 14;

4. BANEA M.D., da SILVA L.F.M., CARBAS R.J.C, DE BARROS S., J. Adhes., 93, 2017, p. 756;

5. NISHIYAMA Y., UTO N., SATO C., SAKURAI H., Int. J. Adhes. Adhes., 23, 2003, p. 377;

6. VIANA G., COSTA M., BANEA M.D., da SILVA L.F.M., Proceedings of the Institution of Mechanical Engineers, Part L: J ournal of Materials: Design and Applications, 231, 2017, p. 488;

7. BANEA M.D., da SILVA L.F.M., CAMPILHO R.D.S.G., J Adhes. Sci. Technol., 28, 2014, p. 1367;

8.BANEA M.D., da SILVA L.F.M., CAMPILHO R.D.S.G., J Adhes. Sci. Technol., 26, 2012, p. 939;

9. BANEA M.D., da SILVA L.F.M., CAMPILHO R.D.S.G., Assembly Automation, 32, 2012, p. 284;

10. ABDEL WAHAB M.M., CROCOMBE A.D., BEEVERS A., EBTEHAJ K., J. Adhes. Adhes., 22, 2002, p. 61;

11. LU M.G., SHIM M.J ., KIM S.W., J. Appl. Polym. Sci., 81, 2001, p. 2253; 12. BANEA M.D., da SILVA L.F.M., CARBAS R.J.C., CAMPILHO R.D.S.G., J. Adhes., 91, 2015, p. 823;

13.BANEA M.D., da SILVA L.F.M., CAMPILHO R.D.S.G., Microsc. Microanal., 21, 2015, p. 7.

Manuscript received: 15.09 .2018 